\title{
Undrained bearing capacity of the cutting face for an open caisson
}

\author{
RONAN ROYSTON*, BRIAN B. SHEIL† and BYRON W. BYRNE
}

\begin{abstract}
Large-diameter open caissons are an increasingly common means of constructing underground storage and attenuation tanks, as well as launch and reception shafts for tunnel-boring machines. A 'cutting face' at the base of the caisson wall, resembling an inclined ring footing, is typically used to aid the sinking phase. This paper describes a suite of over 15000 finite-element limit analyses exploring the bearing capacity of a caisson cutting face, partially or wholly embedded in undrained soil. The primary aim of the study is to assess the influence of the cutting face inclination angle on the vertical bearing capacity. The effects of cutting face roughness, internal overburden and surcharge, and caisson radius are also investigated. In particular, the results indicate that a steepening of the inclination angle may not always reduce the bearing capacity, if the cutting face is rough. The numerical output informs the development of a closed-form approach for application in routine design. The new design method is shown to provide an excellent representation of the numerical output.
\end{abstract}

KEYWORDS: bearing capacity; clays; limit equilibrium methods; numerical modelling

\section{INTRODUCTION}

Large-diameter open caissons are an increasingly common means of constructing underground storage and attenuation tanks, as well as launch and reception shafts for tunnelboring machines (O'Dwyer et al., 2018, 2020). A 'cutting face' at the base of the caisson wall, resembling an inclined ring footing, is commonly used to aid the sinking phase. The purpose of the cutting face is to reduce the vertical bearing capacity and encourage propagation of the soil failure mechanism towards the centre of the caisson for excavation (Sheil et al., 2018). An accurate estimate of the vertical bearing capacity is needed to ensure the caisson self-weight overcomes soil penetration resistances in a controlled manner during the sinking process (Royston et al., 2016).

Although the behaviour of inclined ring footings has received very little treatment in the literature, solutions exist for analogous bearing capacity problems. For example, the bearing capacity of a conical footing depends strongly on the cone apex angle, face roughness and soil conditions (Cassidy \& Houlsby, 2002; Houlsby \& Martin, 2003). Solutions have also been developed for the drained bearing capacity of a flat ring footing, incorporating the effect of soil relative density and the wall diameter-to-thickness ratio (e.g. Vesic, 1975; Bolton \& Lau, 1993; Zhao \& Wang, 2008; Benmebarek et al., 2012). Eurocode 7 (BS EN 1997-1; BSI, 2004) provides guidance on the calculation of the bearing capacity for an inclined strip footing based on earlier work by Hansen (1970). The influence of the inclination angle is considered independent of the footing roughness for undrained soils. Such approaches could be applied to large caisson diameters where the problem can be approximated

Manuscript received 26 June 2020; revised manuscript accepted 21 January 2021. Published online ahead of print 3 March 2021.

Discussion on this paper closes on 1 November 2022, for further details see p. ii.

Published with permission by the ICE under the CC-BY 4.0 license. (http://creativecommons.org/licenses/by/4.0/)

$*$ Ward and Burke Construction Ltd, Bourne End, Bucks, UK; Department of Engineering Science, University of Oxford, Oxford, UK.

$\dagger$ Department of Engineering Science, University of Oxford, Oxford, UK (Orcid:0000-0002-1462-1401).

t Department of Engineering Science, University of Oxford, Oxford, UK (Orcid:0000-0002-9704-0767). to a strip footing. Although the behaviour of strip foundations subjected to inclined loads (e.g. Meyerhof \& Koumoto, 1987; Frydman \& Burd, 1997), as well as the effect of footing embedment (e.g. Meyerhoff, 1951; Hansen, 1970; Salgado et al., 2004), has been well researched, there remains a notable lack of design guidance for inclined axisymmetric footings.

This paper describes a suite of over 15000 finite-element limit analyses (FELAs) exploring the undrained bearing capacity of a large-diameter caisson cutting face. The main objective of the research is to identify the most influential caisson and soil parameters for the vertical bearing capacity of the cutting face. The numerical results are used to inform the development of a new closed-form design approach, which captures the influence of inclination and roughness of the cutting face, internal overburden and surcharge, and the caisson radius. The new design method is applied to a realistic design scenario to allow comparisons with calculations using Eurocode 7 (BSI, 2004) design guidelines.

\section{PROBLEM DEFINITION}

Figure 1 defines the problem and notation for this study. The geometry of the caisson cutting face is described by the angle of inclination, $\beta$, embedded width, $B$, internal radius, $R$, and cross-sectional area, $A$. The caisson is considered partially or wholly embedded in homogeneous undrained clay with unit weight $\gamma_{\mathrm{s}}$ and undrained shear strength $s_{\mathrm{u}}$. The embedded depth of the vertex of the cutting face relative to the internal excavation level is given by $h_{\mathrm{v}}$, whereas $h$ defines the internal soil overburden (see Fig. 1). In practice, an open caisson is commonly launched within a cofferdam such that the external soil overburden is significantly greater than the internal overburden. The external soil surface was therefore restricted from vertical movement to approximate field behaviour. The undrained shear strength of the interface between the soil and cutting face is $\alpha s_{\mathrm{u}}$, where $\alpha$ is the adhesion factor and is varied between 0 (smooth) and 1 (rough). At a vertical penetration of $w$, the vertical and horizontal reaction exerted by the soil on the cutting face is $V$ and $H$, respectively. A dimensionless bearing capacity factor, $N$, can be obtained from $V$ using equations (1) and (2) as follows

$$
N_{\mathrm{ps}}=\frac{V_{\mathrm{ps}}}{s_{\mathrm{u}} B}
$$




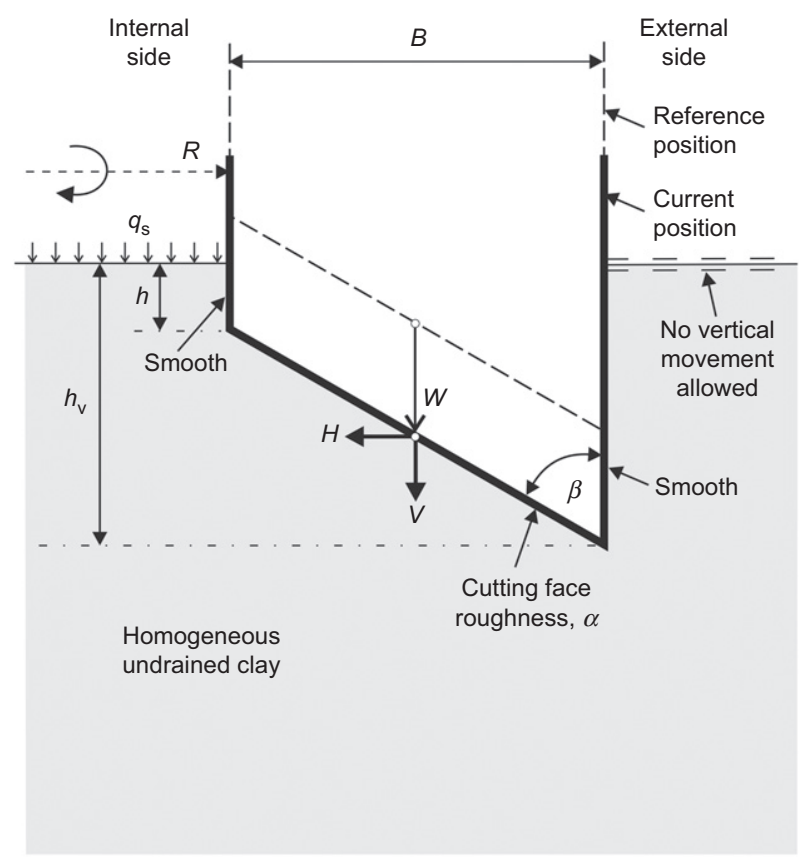

Fig. 1. Definition of problem and notation

$$
N_{\mathrm{axi}}=\frac{V_{\mathrm{axi}}}{s_{\mathrm{u}} A}
$$

where the subscripts 'ps' and 'axi' denote plane-strain and axisymmetric conditions, respectively.

\section{FINITE-ELEMENT LIMIT ANALYSIS \\ Overview}

The numerical analyses were performed using the twodimensional (2D) version of the in-house FELA software OxLim developed by C. M. Martin at the University of Oxford, UK. It has been used extensively for the analysis of both plane-strain and axisymmetric problems - for example, Martin (2011), Martin \& White (2012) and Dunne \& Martin (2017). The program computes strict lower-bound (LB) and upper-bound (UB) plasticity solutions using the methods described by Makrodimopoulos \& Martin (2006, 2007, 2008). The average of the bounds, $(\mathrm{LB}+\mathrm{UB}) / 2$, is used as the best estimate solution, and the associated bracketing error is calculated as $\pm(\mathrm{UB}-\mathrm{LB}) /(\mathrm{UB}+\mathrm{LB})$. The classical assumptions of limit analysis apply: all materials and interfaces are rigid-plastic and obey the associated flow (or normality) rule. Adaptive remeshing, based on the maximum shear strain rate in the UB velocity field, is used to ensure that these bounds bracket the exact collapse load very closely (to within $1.5 \%$ or better for this work). A von Mises failure criterion was adopted for the soil, allowing both LB and UB analyses to be cast as standard second-order cone programming problems and solved using the software program Mosek. For this study all mesh generation was performed using the opensource code Triangle. Further information can be found in Makrodimopoulos \& Martin (2006, 2007, 2008) and Martin (2011).

\section{Modelling preliminaries}

The soil domain was sized to comfortably contain the soil failure mechanism for all soil/caisson parameter combinations considered. The width of the soil domain was taken as the maximum of $9 B$ or $1.5 \mathrm{~h}$ and the depth of the domain was taken as the maximum of $6 B$ or $0.6 \mathrm{~h}$. The

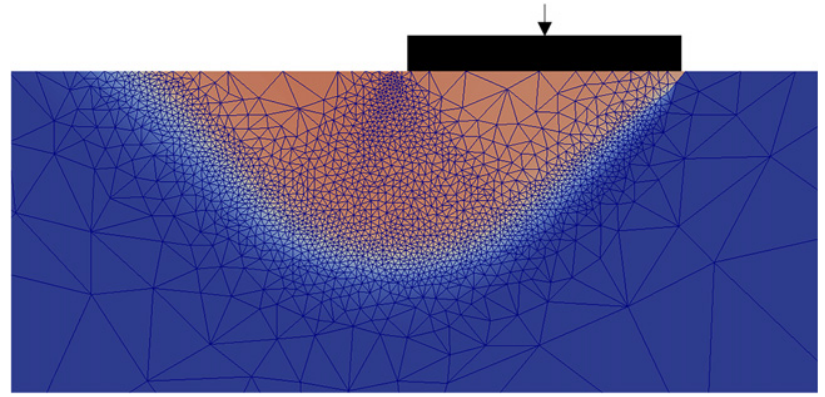

Fig. 2. Exemplar finite-element mesh adopted using OxLim for a conventional flat rough strip footing on a level bed of undrained soil after seven rounds of adaptive remeshing based on shear strain rates

lateral boundaries were restricted from movement normal to the respective surface, whereas the bottom boundary was restrained from movement in both directions.

The following stages of analysis were adopted in the modelling.

(a) Wished-in-place installation of a weightless, rigid cutting face, with an embedded width of $B=1 \mathrm{~m}$, in undrained soil with $s_{\mathrm{u}}=1 \mathrm{kPa}$ and unit weight of $\gamma_{\mathrm{s}}$. The footing was restrained in all three degrees of freedom during this calculation phase.

(b) Application of a downward load multiplier until failure is achieved. During this step, horizontal translation and rotation of the footing were prevented. The treatment of the penetration problem in this way tacitly assumes that the caisson behaves as a rigid body during the sinking process.

Figure 2 shows an exemplar FELA mesh after seven rounds of adaptive remeshing (a flat rough strip footing is shown for illustrative purposes). Also superimposed on the figure are the velocities determined from the UB analysis. It can be seen that the UB velocities and refined mesh provide an effective means of revealing the associated soil failure mechanism.

\section{VALIDATION}

A validation exercise explored computation of the vertical bearing capacity for a surface strip footing on soil with uniform strength. An exact analytical solution is available $(N=2+\pi$; Prandtl, 1922), independent of footing roughness. The OxLim LB and UB solutions were found to bracket the exact solution to within the target bracketing precision of $1 \cdot 5 \%$. The load factor from OxLim after seven iterations is $5 \cdot 163$, in excellent agreement with the exact solution of $5 \cdot 142$ (Prandtl, 1922).

\section{FELA RESULTS AND DESIGN METHOD DEVELOPMENT \\ Overview}

Automated batches of OxLim analyses were performed considering all combinations of the following parameters

(a) cutting face angle: $\beta=30^{\circ}, 45^{\circ}, 60^{\circ}, 75^{\circ}, 90^{\circ}$

(b) cutting face roughness: $\alpha=0,0 \cdot 2,0 \cdot 4,0 \cdot 6,0 \cdot 8,1 \cdot 0$

(c) dimensionless internal surcharge: $q_{\mathrm{s}} / s_{\mathrm{u}}=0$ or 1

(d) dimensionless weight-to-strength ratio: $\gamma_{\mathrm{s}} B / s_{\mathrm{u}}=0$ or 1

(e) dimensionless internal overburden: $h / B=0,0 \cdot 1,0 \cdot 2$, $0 \cdot 3,0 \cdot 4,0 \cdot 5,1,2,4,6,8,10$

( $f$ ) dimensionless caisson radius: $R / B=2,4,6,8,10,12$, $14,16,18,20, \infty$ (plane strain). 
Table 1. Notation adopted for OxLim-derived undrained bearing capacity factors of a caisson cutting face

\begin{tabular}{l|l}
\hline Variable & Description \\
\hline$N_{\mathrm{ps}, \mathrm{h}=0}$ & $\begin{array}{l}\text { Bearing capacity factor for plane-strain conditions } \\
\text { and } h \leq 0 \text { only } \\
N_{\mathrm{ps}}\end{array}$ \\
$\begin{array}{l}\text { Bearing capacity factor for generalised plane-strain } \\
\text { conditions } \\
N_{\mathrm{axi}}\end{array}$ & $\begin{array}{c}\text { Bearing capacity factor for generalised plane-strain } \\
\text { and axisymmetric conditions }\end{array}$ \\
\hline
\end{tabular}

The analyses assume that the space above the cutting face is occupied by a rigid, smooth-sided wall, based on empirical evidence of the effectiveness of an external annulus and interface lubrication during caisson sinking in undrained soils (Royston, 2018; Royston et al., 2020). It has also been observed that the penetration of the angled cutting face into the clay does not necessarily lead to contact between the disturbed soil and the interior caisson wall (Royston, 2018). Therefore, only the roughness of the cutting face is considered in the subsequent analyses to simulate realistic conditions in practice. Complexity is added to the analysis of the vertical bearing capacity in three stages: $(a)$ stage I, plane-strain cutting face with no internal overburden $(h / B \leq 0, R / B=\infty) ;(b)$ stage II, generalised plane-strain cutting face $(h / B=$ any, $R / B=\infty)$; and $(c)$ stage III, generalised axisymmetric cutting face $(h / B=$ any, $R / B=$ any). Notation for the OxLim-derived bearing capacity factors is defined in Table 1 for each stage.

Stage I: plane-strain cutting face with no internal overburden $(\mathrm{h} / \mathrm{B} \leq 0, \mathrm{R} / \mathrm{B}=\infty)$

For the stage I analyses the range of $20^{\circ} \leq \beta \leq 90^{\circ}$ was explored in increments of $\beta=5^{\circ}$. Fig. 3 shows the influence of both $\beta$ and $\alpha$ on $N_{\mathrm{ps}, \mathrm{h}=0}$. For a smooth cutting face, $N_{\mathrm{ps}, \mathrm{h}=0}$ is a linear function of $\beta$. An increase in roughness causes the relationship between $N_{\mathrm{ps}, \mathrm{h}=0}$ and $\beta$ to become non-linear, with an optimal angle existing for $\alpha \geq 0.4$ for the practical range of $\beta$. Importantly, the results indicate that a steepening of the inclination angle may not always reduce the bearing capacity if the cutting face is rough.

Figure 4 shows the influence of $\beta$ on the developed soil failure mechanisms using OxLim-predicted UB velocity

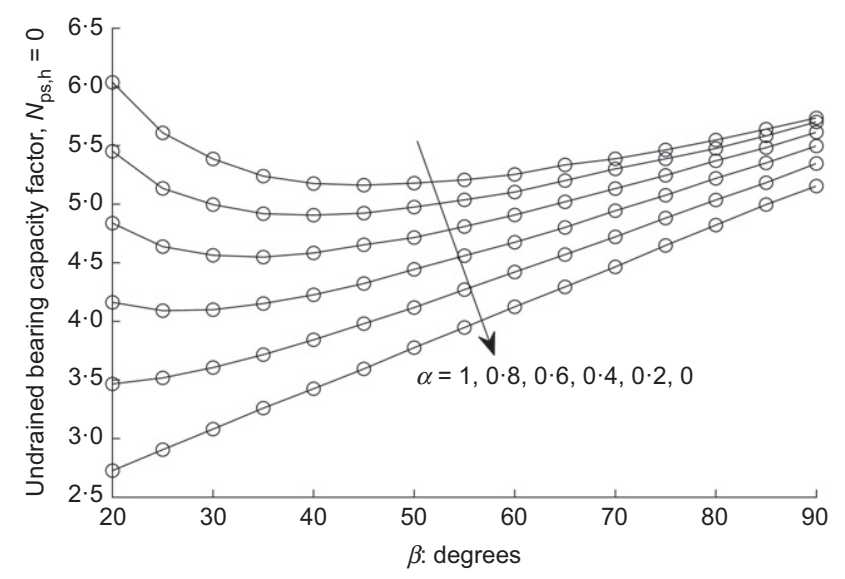

Fig. 3. FELA predictions of the influence of the cutting face inclination angle on the bearing capacity factor for $h / B \leq 0$ and values of $\alpha$ ranging between 0 and $1 ; \gamma_{\mathrm{s}} B / s_{\mathrm{u}}=0, q_{\mathrm{s}} / s_{\mathrm{u}}=0, \bar{h} / B=0$, $R I B=\infty$ (plane strain) fields for both a smooth and rough cutting face, with the inferred geometry for each failure mechanism superimposed. Considering first the $\alpha=0$ results, while a reduction in $\beta$ appears to increase the size of the failure mechanism, this is offset by a reduction in the corresponding UB velocity field; this ultimately leads to the reduction in bearing capacity observed in Fig. 3. In contrast, the non-linear relationship observed in Fig. 3 for $\alpha=1$ is due to a much greater increase in the size of the failure zone for $\beta=30^{\circ}$ (see Fig. 4). Based on the failure mechanisms identified, a kinematic mechanism is proposed in Fig. 5. Three main zones are identified: (a) the rigid wedge $\mathrm{OCD}$ with $\phi=45^{\circ}$ and $0^{\circ}$ for a smooth and rough cutting face, respectively; (b) the shear fan zone OBC; and (c) the rigid wedge $\mathrm{OAB}$, which is also an isosceles right triangle. For a smooth and a rough cutting face, the angle of the fan zone, $\theta$, is $\beta$ and $\beta+45^{\circ}$, respectively. The failure mechanism shown in Fig. 5 leads to the following theoretical expression for $N_{\mathrm{ps}, \mathrm{h}=0}$

$$
N_{\mathrm{ps}, \mathrm{h}=0}=\left[2\left(\frac{\beta}{180^{\circ}} \pi\right)+2\right]+\left(\frac{\alpha}{\tan \beta}\right)+\left(\alpha+\frac{\pi-4}{2} \alpha^{2}\right)
$$

The first term on the right-hand side of equation (3) defines the bearing capacity factor for $\alpha=0$, which was observed to be a linear function of $\beta$ in Fig. 3. This term reduces to the exact solution of $\pi+2$ for a conventional flat strip footing (Prandtl, 1922). A substantial part of the effect of cutting face roughness is accounted for by the vertical component of the shear force developed on the inclined cutting face. This is captured by the second term in equation (3). The third term captures the contribution from normal pressure acting on the cutting face.

Owing to asymmetry about the vertical axis of the cutting face, the influence of soil unit weight on the bearing resistance necessitates explicit treatment. The additional resistance contribution attributed to soil unit weight is therefore captured by the second term on the right-hand side of equation (4) and is a function of $\beta$ and the vertical embedment of the cutting face - that is, $h_{\mathrm{v}}=B / \tan \beta$. The final term of equation (4) captures the influence of the internal surcharge pressure, $q_{\mathrm{s}}$.

$$
V_{\mathrm{ps}, \mathrm{h}=0}=\left(N_{\mathrm{ps}, \mathrm{h}=0} s_{\mathrm{u}}+\frac{\gamma_{\mathrm{s}} B}{2 \tan \beta}+q_{\mathrm{s}}\right) B
$$

Stage II: generalised plane-strain cutting face $(\mathrm{h} / \mathrm{B}=$ any, $\mathrm{R} / \mathrm{B}=\infty$ )

Additional FELA-predicted soil failure mechanisms for a typical caisson embedment of $h / B=2$ are presented in Fig. 6 . The influence of cutting face embedment on the soil failure mechanism can be assessed through comparison of the results presented in Figs 4 and 6. Soil weight effects aside, it can be seen that an increase in $h / B$ influences the bearing capacity by increasing the extent of the soil failure surface. From Fig. 6, it is also apparent that the developed failure mechanisms are similar for all values of $\beta$ and $\alpha$, and are therefore dominated by the embedment depth. The change in curvature of the soil failure mechanism in the region above the cutting face is also an interesting feature.

Figure 7 plots the variation of $N_{\mathrm{ps}}$ as a function of $h / B$, where a non-linear relationship is evident. Although a rough cutting face exhibits higher $N_{\mathrm{ps}}$, the increment of $N_{\mathrm{ps}}$ with $h / B$ appears near-independent of $\alpha$. It can also be seen that $\beta$ has a greater influence on the bearing capacity for $\alpha=0$ compared to $\alpha=1$. These data have been re-plotted in Fig. 8, except values of $N_{\mathrm{ps}}$ have now been zeroed at $h / B=0$ (by 

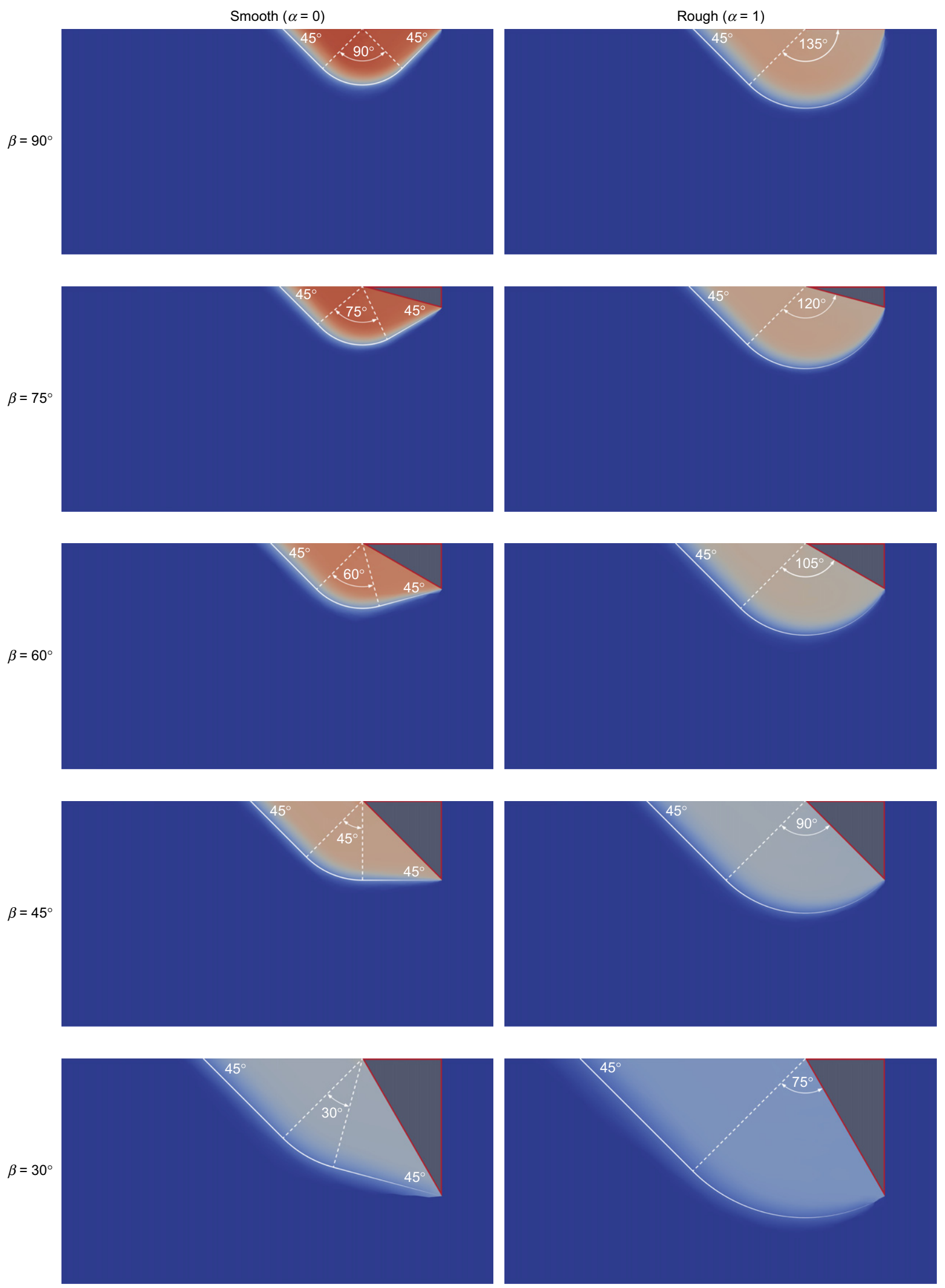

Fig. 4. Contours of UB velocities determined by FELA showing the influence of $\beta$ on soil failure mechanisms for $h / B=0$ and for a smooth and rough cutting face. The inferred geometry of each failure mechanism is superimposed on the respective figure using a white line. $\gamma_{\mathrm{s}} B / s_{\mathrm{u}}=0$, $q_{\mathrm{s}} / s_{\mathrm{u}}=\mathbf{0}, R / B=\infty$ (plane strain)

subtracting corresponding values of $\left.N_{\mathrm{ps}, \mathrm{h}=0}\right)$. Manipulating the bearing capacity factors in this way reveals a bound on $N_{\mathrm{ps}}-N_{\mathrm{ps}, \mathrm{h}=0}$ for $\beta \geq 50^{\circ}$. Although there is improved agreement between the results, there remains a slight dependency of these trends on both $\alpha$ and $\beta$. In light of these results, it is found empirically that $N_{\mathrm{ps}}$ can be expressed in the 


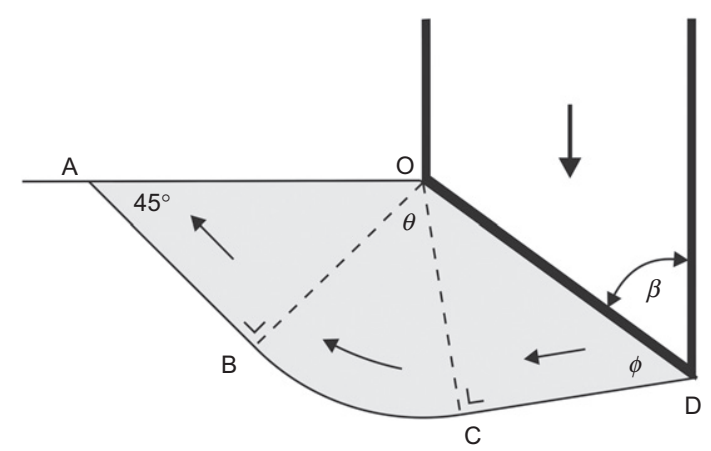

Fig. 5. Proposed theoretical failure mechanism for an inclined cutting face with $h / \mathrm{B} \leq 0$ based on FELA results presented in Fig. 4

following form

$$
\begin{aligned}
N_{\mathrm{ps}} & =N_{\mathrm{ps}, \mathrm{h}=0}+\left[\frac{(h / B)^{0.452}}{\cos \beta+0 \cdot 133 \alpha}\right] \\
& \leq N_{\mathrm{ps}, \mathrm{h}=0}+\left[\frac{(h / B)^{0.452}}{\cos \left(50^{\circ}\right)+0 \cdot 133 \alpha}\right]
\end{aligned}
$$

where $N_{\mathrm{ps}, \mathrm{h}=0}$ is obtained from equation (3). The form of equation (5) was obtained by curve-fitting the OxLim results presented in Fig. 8, the parameters and exponents of which were determined using a least-squares goodness-of-fit measure. These empirical parameters implicitly account for the non-linearity of the soil failure surface and the potential for interface shear stresses to not fully reach $\alpha s_{\mathrm{u}}$. The vertical bearing resistance also includes an additional term to account for the weight of the additional soil overburden

$$
V_{\mathrm{ps}}=\left(N_{\mathrm{ps}} s_{\mathrm{u}}+\frac{\gamma_{\mathrm{s}} B}{2 \tan \beta}+q_{\mathrm{s}}+\gamma_{\mathrm{s}} h\right) B
$$

Stage III: generalised axisymmetric cutting face $(\mathrm{h} / \mathrm{B}=$ any, $\mathrm{R} / \mathrm{B}=$ any)

In this stage, the analyses were extended to consider the dimensionless caisson radius, $R / B$, which influences the bearing capacity by two competing mechanisms. First, footings with smaller radii develop increased bearing capacity due to a reduction in the circumferential length of the failure surface and therefore an increase in the shear strain (see Fig. 9). However, for deeply embedded footings with small radii, there is an interception, and therefore shortening, of the failure surface leading to a lower bearing capacity, as shown in Fig. 10. It follows that for deeply embedded cutting faces, a reduction in bearing capacity (arising from a reduction in the extent of the failure surface) dominates and vice versa for shallow embedments.

Stage III bearing capacity factors, $N_{\text {axi }}$, are plotted against the reciprocal of $R / B$ in Fig. 11. To ensure the analyses cover all values likely to be encountered in practice, a wide range of $B / R$ has been considered (where $B / R=0$ corresponds to plane-strain conditions). Fig. 11 plots the influence of $B / R$ on $N_{\text {axi }}$ for values of $\beta$ of $30^{\circ}, 45^{\circ}, 60^{\circ}, 75^{\circ}, 90^{\circ}$ and for a smooth and rough cutting face. From Fig. 11, it can be seen that the development of $N_{\text {axi }}$ is a linear response to an increase in $B / R$ before transitioning to a 'backbone curve'. The linear portion represents the influence of the radial stress increase on the bearing capacity, whereas the backbone curve dominates when the failure planes intercept and do not extend to the surface (see Fig. 10(b), for example). The slopes, $m$, of these linear portions are plotted in Fig. 12 as a function of $h / B$. Conveniently, there is strong linearity in the data where a best-fit line is described by the following expression

$$
m=\frac{\mathrm{d} N_{\text {axi }}}{\mathrm{d}(B / R)}=\frac{8}{9}-\frac{2}{3}\left(\frac{h}{B}\right)
$$

In the case of the backbone curve, the failure mechanism forms a logarithmic spiral towards the caisson centreline and the soil above the cutting face displaces vertically upwards, as shown in Fig. 10(b). The stage III bearing capacity can therefore be defined as follows

$$
\begin{aligned}
N_{\mathrm{axi}}= & N_{\mathrm{ps}}+m(B / R) \leq A_{\mathrm{b}} \ln (B / R)+B_{\mathrm{b}}(B / R) \\
& +C_{\mathrm{b}}\left[\left(\frac{\beta}{180^{\circ}} \pi\right)-\frac{\pi}{6}\right]+\frac{\alpha}{\tan \beta}+\alpha(B / R)
\end{aligned}
$$

where the left-hand and right-hand sides of the inequality represent the linear and backbone portions, respectively, of the curves in Fig. 11; $A_{\mathrm{b}}$ controls the shape of the backbone curve; and $B_{\mathrm{b}}$ and $C_{\mathrm{b}}$ control the influence of $B / R$ and $\beta$, respectively. The parameters $A_{\mathrm{b}}, B_{\mathrm{b}}$ and $C_{\mathrm{b}}$ were determined as $-2 \cdot 162,4 \cdot 277$ and $2 \cdot 52$ by optimisation against the FELA results. The last two terms to the right of the inequality account for the role of $\alpha$ as a function of $\beta$ and $B / R$.

\section{DESIGN METHOD VERIFICATION}

An overview of the design methodology is presented in Fig. 13. The new approach is verified by comparison against the results for the 15000 OxLim analyses completed in the study. The percentage error between predictions determined using the new approach and OxLim are plotted against normalised embedment depth in Fig. 14. The simplified design approach provides a very good representation of the OxLim output, with a maximum deviation of $\sim 5 \%$ and a slight bias on the safe side (overall mean $=-0.39 \%$ ). The error increases for greater embedment depths due to the difficulty in describing the shape of the backbone curve, and its dependence on the caisson/soil parameters, using simplified closed-form equations.

\section{Comparison to Eurocode 7}

A comparison of the new design method to that in Eurocode 7 (BS EN 1997-1; BSI, 2004) considers a recent caisson construction project described in Royston (2018). The adopted caisson/soil parameters are summarised in Table 2 (Royston, 2018). Fig. 15 shows the influence of $\beta$ on the predicted total caisson embedment $\left(h_{\mathrm{v}}\right)$ caused by the downward force provided by the construction of the concrete caisson walls. The total downward force, $V_{\text {axi }}$, is calculated from the wall volume, using $25 \mathrm{kN} / \mathrm{m}^{3}$ for the unit weight of concrete. Also shown on Fig. 15 are the corresponding predictions determined using solutions for an inclined strip footing outlined in Eurocode 7 (BS EN 1997-1; BSI, 2004)

$$
\begin{aligned}
& N_{\mathrm{EC} 7}=(\pi+2) i+q / s_{\mathrm{u}} \\
& i=1-\left[\frac{\pi-\left(\pi \beta / 180^{\circ}\right)}{\pi+2}\right]
\end{aligned}
$$

where the parameter $q$ is the 'overburden or surcharge pressure' at the level of the foundation base. As the Eurocode 7 approach (BS EN 1997-1; BSI, 2004) corresponds to a plane-strain analysis, these comparisons are only indicative. Nevertheless, both sets of predictions exhibit a distinct inflection point when the cutting face becomes fully embedded at $h_{\mathrm{v}}=t / \tan \beta$, where $t$ is the total wall thickness. The Eurocode 7 methodology (BS EN 1997-1; BSI, 2004), however, predicts a significantly greater embedment for a given wall height than the present 

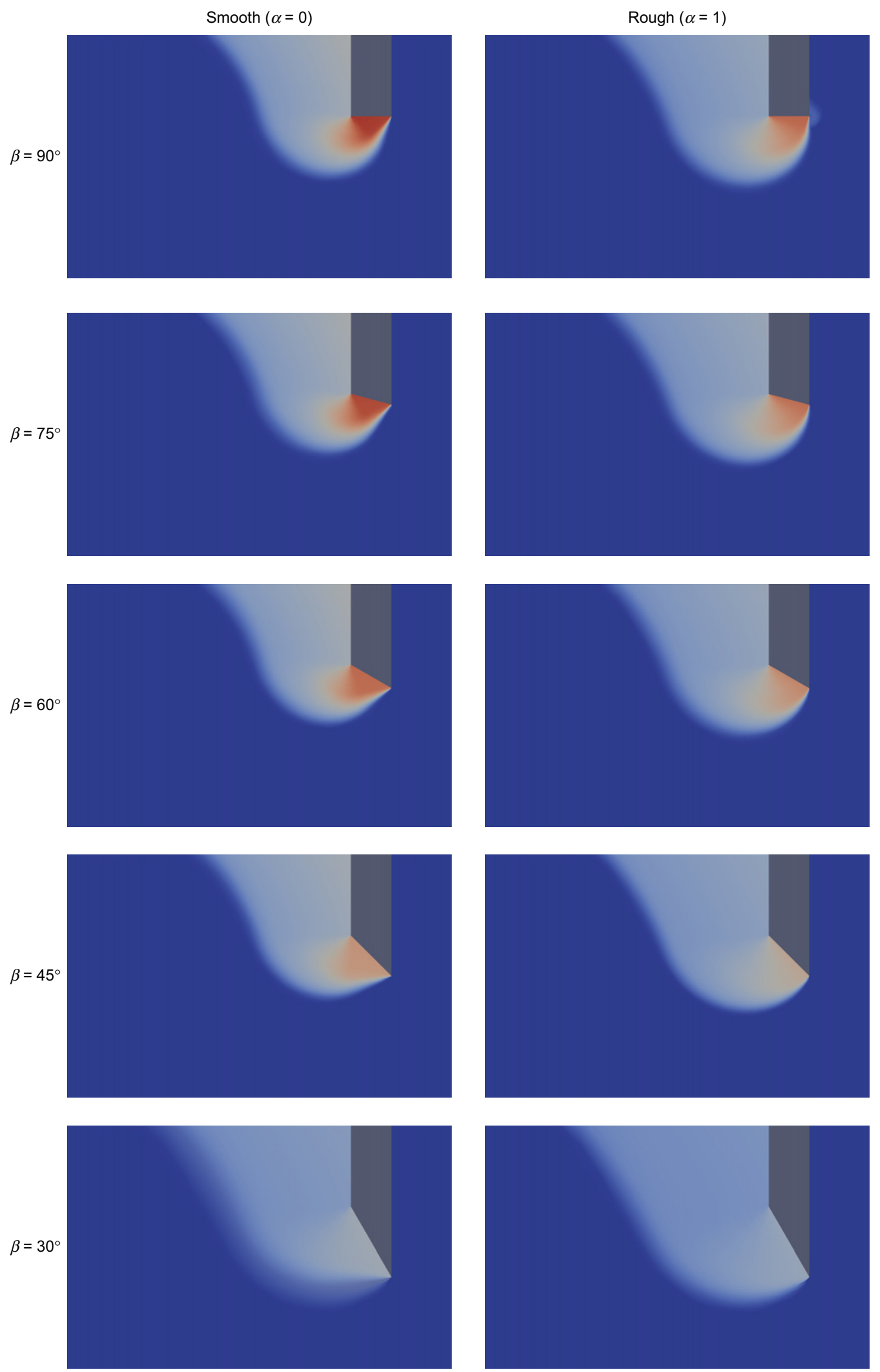

Fig. 6. Contours of UB velocities determined by FELA showing the influence of $\beta$ on soil failure mechanisms for $h / B=2$ and for a smooth and rough cutting face; $\gamma_{\mathrm{s}} B / s_{\mathrm{u}}=0, q_{\mathrm{s}} / s_{\mathrm{u}}=0, R / B=\infty$ (plane strain)

design approach. It should be noted that this under-prediction of the capacity of the cutting face is unconservative for open caisson construction. This discrepancy is a result of the following limitations of the Eurocode 7 approach (BSI, 2004) approach: (a) for deeply embedded footings the method does not consider the extension of the failure surface into the additional soil overburden; (b) axisymmetric radial stress increases are not considered; and $(c)$ cutting face roughness and inclination angle are assumed independent.

\section{CONCLUSIONS}

This paper has described a numerical study of the ultimate undrained bearing capacity of an open caisson cutting 


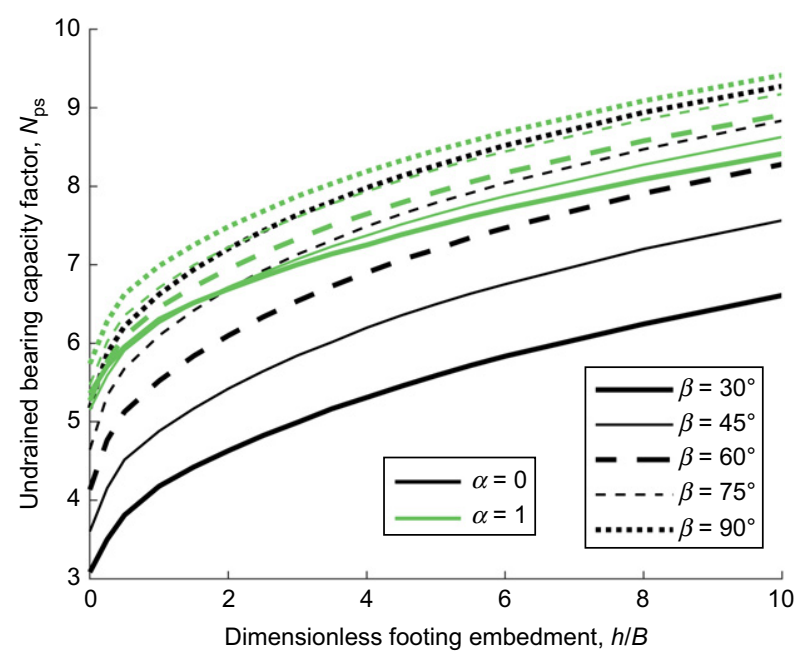

Fig. 7. FELA predictions of the influence of dimensionless footing embedment on the bearing capacity factor of a smooth and rough cutting face; $\gamma_{\mathrm{s}} B / s_{\mathrm{u}}=0, q_{\mathrm{s}} / s_{\mathrm{u}}=0, R / B=\infty$ (plane strain)

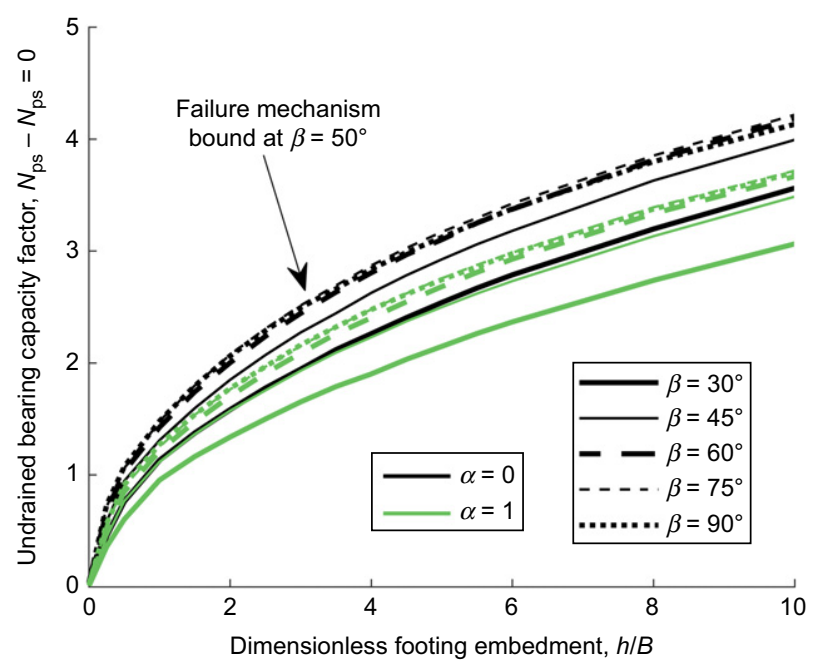

Fig. 8. FELA predictions of the influence of dimensionless footing embedment on the relative bearing capacity factor for a smooth and rough cutting face; $\gamma_{\mathrm{s}} B / s_{\mathrm{u}}=0, q_{\mathrm{s}} / s_{\mathrm{u}}=0, R / B=\infty$ (plane strain)

face. FELA was used to identify the most influential caisson/ soil parameters, providing the basis for a new closed-form design method. The main conclusions from the study are as follows.

(a) The undrained bearing capacity factor was shown to be highly dependent on the angle of inclination of the cutting face. For a smooth cutting face, the bearing capacity factor is a linear function of the cutting face inclination angle. For non-smooth footings, the relationship becomes non-linear where an optimum angle of inclination exists. The results indicate that a steepening of the inclination angle may not always reduce the bearing capacity if the cutting face is rough.

(b) Two competing influences on bearing capacity were identified for an axisymmetric cutting face compared to equivalent plane-strain conditions. First, cutting faces with smaller radii develop increased bearing capacity due to an increase in radial stress. For deeply embedded cutting faces with small radii, however, there is an interception, and therefore shortening, of the failure surface leading to a lower

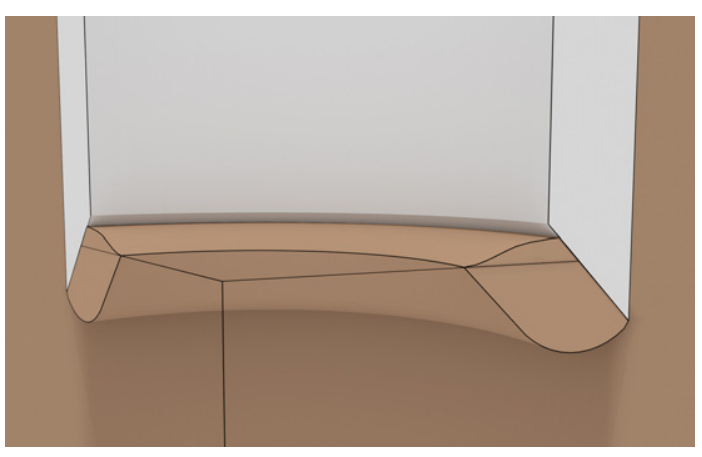

(a)

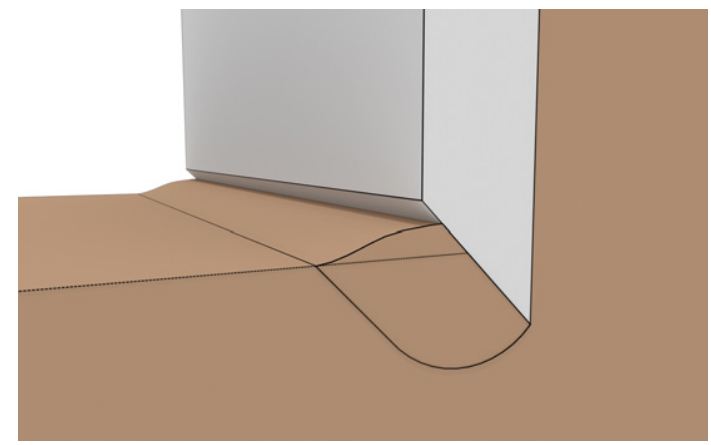

(b)

Fig. 9. Schematic diagram showing typical (a) plane strain and (b) axisymmetric failure mechanisms

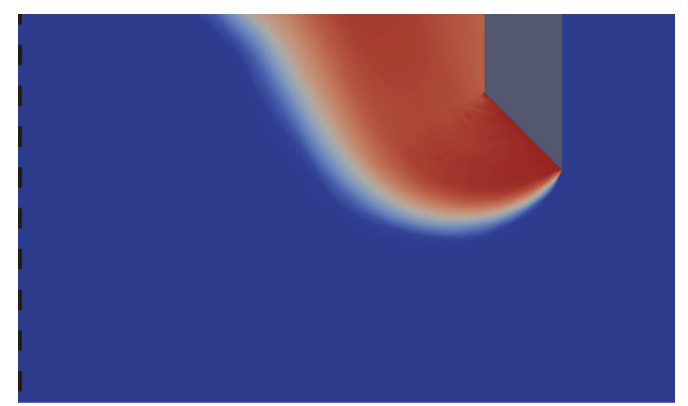

(a)

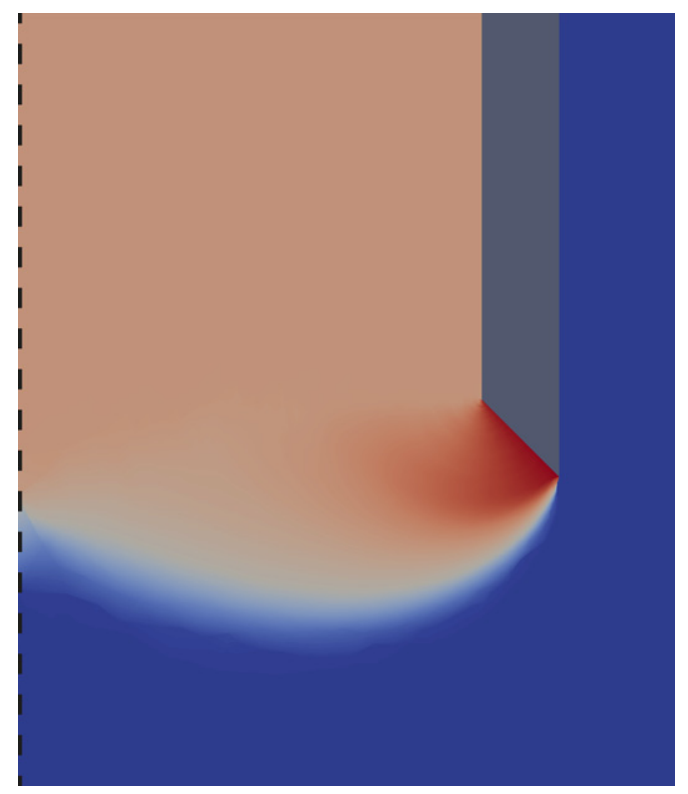

(b)

Fig. 10. Contours of UB velocities determined by FELA showing the influence of embedment depth on soil failure mechanisms for a smooth cutting face: (a) $h l B=1$; (b) $h l B=6 . R / B=6, \gamma_{\mathrm{s}} B / s_{\mathrm{u}}=0, q_{\mathrm{s}} / s_{\mathrm{u}}=0$ 


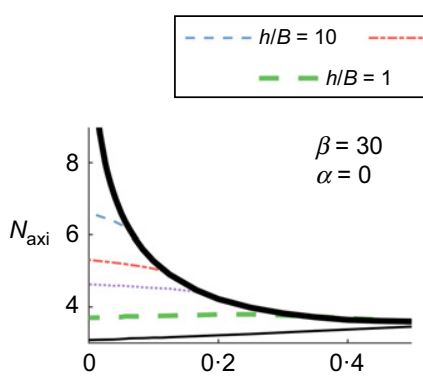

$h / B=4 \quad h \cdots \cdots \cdots \cdots+\cdots \cdot h=2$
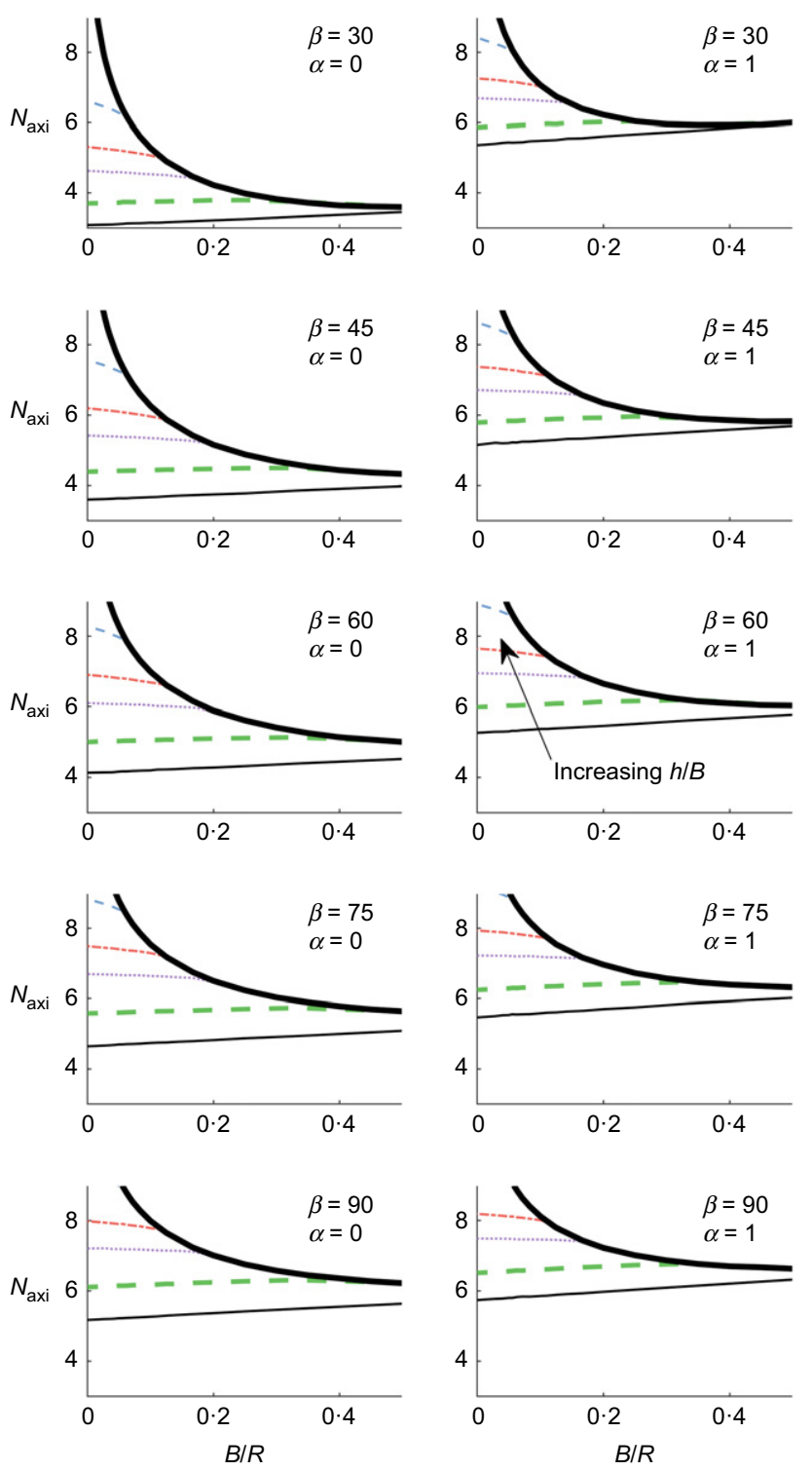

Fig. 11. FELA predictions of the influence of dimensionless caisson radius on the bearing capacity of a smooth and rough cutting face and for a range of inclination angles. Note only select values of $h / B$ are presented for the sake of clarity

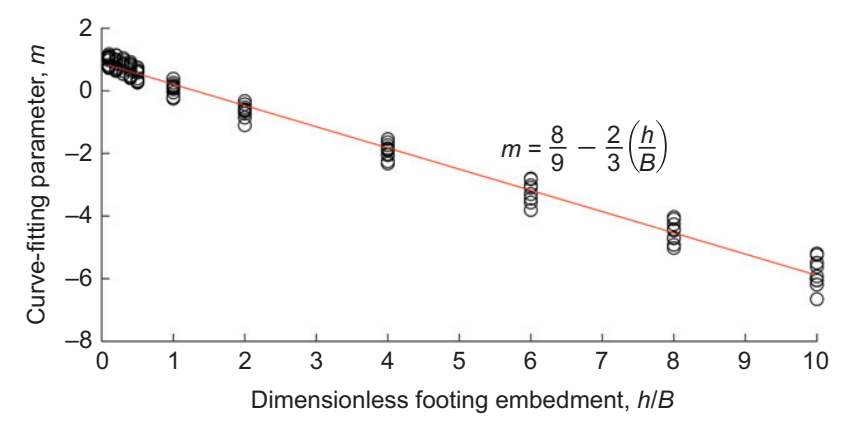

Fig. 12. Dependence of curve-fitting parameter $m$ on dimensionless footing embedment showing best-fit linear relationship and coefficient of correlation. These data points were determined by fitting a linear trendline to the linear portions of the FELA results presented in Fig. 11 for all axisymmetric analyses

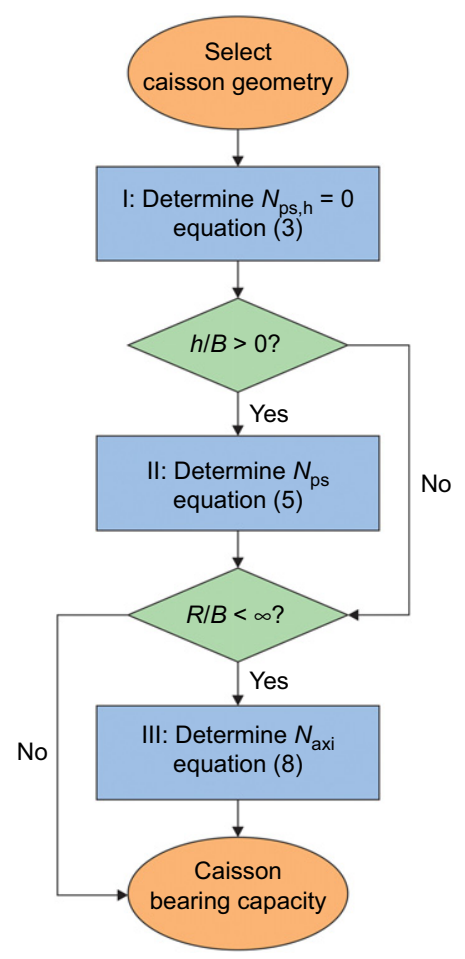

Fig. 13. Flow chart for the determination of caisson bearing capacity using the proposed design methodology

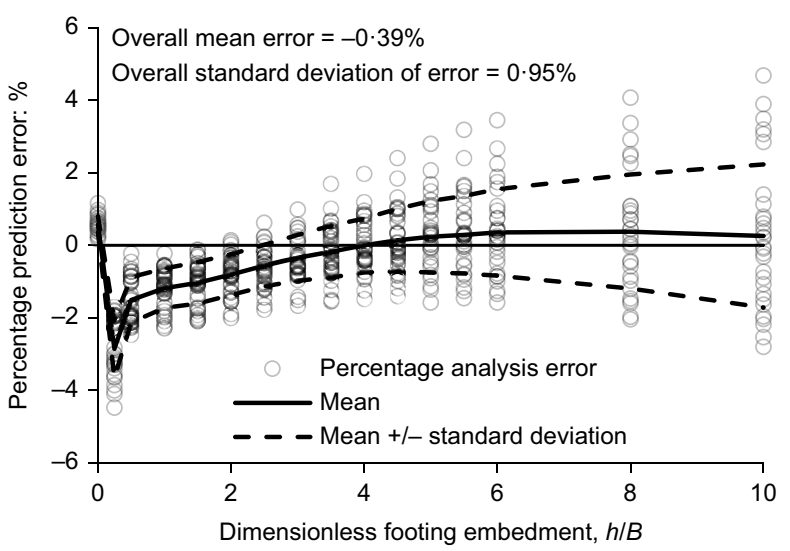

Fig. 14. Percentage error between bearing capacity predictions determined using new design approach and those determined using OxLim plotted against dimensionless embedment depth

bearing capacity. It follows that for deep embedments, reduction in bearing capacity arising from a reduction in the extent of the failure surface dominates, and vice versa for shallow embedments.

(c) A closed-form predictive approach, amenable for use in routine design, was developed based on the results of the FELA. The method allows for the determination of the vertical bearing capacity and captures all salient dimensionless groups identified in the numerical parametric study. The design approach was shown to provide a very good representation of the numerical data.

(d) Homogeneous soil conditions were assumed in the modelling presented in this paper. In all instances, the numerical results showed that the soil failure mechanism extended internally. For application of the design methodology developed to projects with varying soil conditions, the adopted soil 
Table 2. Caisson/soil parameters reported by Royston (2018) used for Eurocode 7 (BS EN 1997-1; BSI, 2004) comparisons

\begin{tabular}{l|c}
\hline Parameter & Value \\
\hline Caisson internal radius, $R: \mathrm{m}$ & 11 \\
Caisson wall thickness, $t: \mathrm{m}$ & 1 \\
Cutting face roughness, $\alpha$ & 1 \\
Internal surcharge, $q_{\mathrm{s}}: \mathrm{kPa}$ & 0 \\
Soil undrained shear strength, $s_{\mathrm{u}}: \mathrm{kPa}$ & 40 \\
Soil unit weight, $\gamma_{\mathrm{s}}: \mathrm{kN} / \mathrm{m}^{3}$ & 16 \\
Unit weight of caisson wall, $\gamma_{\mathrm{c}}: \mathrm{kN} / \mathrm{m}^{3}$ & 25
\end{tabular}

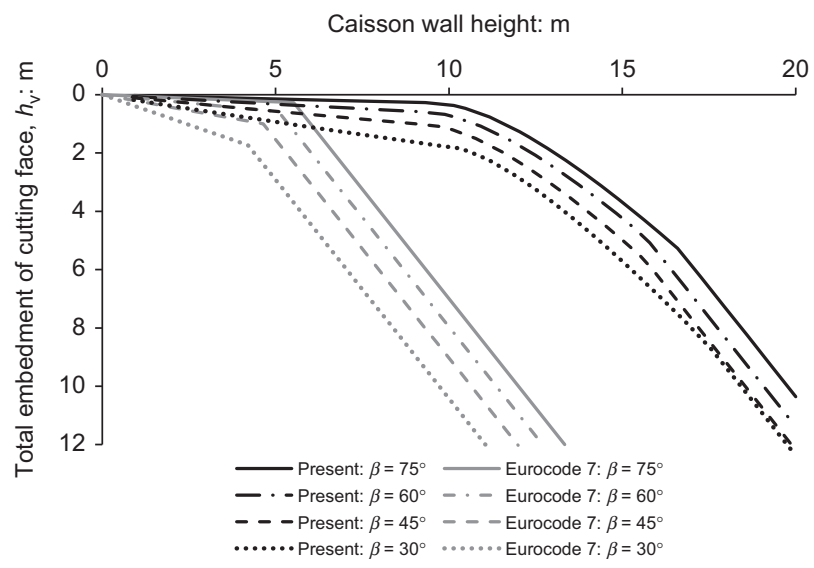

Fig. 15. Comparison between new method and Eurocode 7 (BSI, 2004) predictions for the required caisson embedment to achieve equilibrium during wall construction for values of $\beta$ of $30^{\circ}, \mathbf{4 5}^{\circ}, \mathbf{6 0}^{\circ}$ and $75^{\circ}$. Adopted caisson/soil parameters are listed in Table 2

strength should therefore reflect conditions at the internal excavation level.

(e) The FELAs conducted in this paper consider the cutting face wished-in-place and therefore do not consider any large-strain soil behaviour or soil heave that may occur during the sinking process. The analyses, and the design methodology presented, also assume that no consolidation occurs during construction due to the typically short excavation and sinking phases in practice.

\section{ACKNOWLEDGEMENTS}

The authors gratefully acknowledge the financial support provided by Ward and Burke Construction Ltd for this research. The second and third authors were funded by the Royal Academy of Engineering under the Research Fellowship and Research Chair Schemes, respectively. The authors acknowledge Professor Chris Martin for his input and for providing a copy of the OxLim software program for this work.

\section{NOTATION}

$A$ cross-sectional area of caisson wall

$A_{\mathrm{b}} \quad$ empirical curve-fitting parameter controlling the shape of the backbone curve

$B$ embedded wall width of caisson

$B_{\mathrm{b}} \quad$ empirical curve-fitting parameter controlling the influence of $B / R$

$C_{\mathrm{b}}$ empirical curve-fitting parameter controlling the influence of $\beta$

$h$ internal soil overburden $h_{\mathrm{v}}$ embedded depth of the vertex of the cutting face relative to the internal excavation level

$m$ empirical curve-fitting parameter

$N_{\text {axi }}$ dimensionless bearing capacity factor for generalised axisymmetric conditions

$N_{\text {EC7 }}$ solutions for the dimensionless bearing capacity factor of an inclined strip footing outlined in Eurocode 7, BS EN 1997-1 (BSI, 2004)

$N_{\mathrm{ps}}$ dimensionless bearing capacity factor for generalised plane-strain conditions

$N_{\mathrm{ps}, \mathrm{h}=0} \quad$ dimensionless bearing capacity factor for plane-strain conditions and level internal excavation level $(h=0)$

$q_{\mathrm{s}} \quad$ surcharge applied to internal soil surface

$R$ internal radius of caisson

$s_{\mathrm{u}} \quad$ undrained shear strength of soil

$t$ total caisson wall thickness

$V_{\text {axi }}$ vertical soil reaction for axisymmetric conditions

$V_{\mathrm{ps}} \quad$ vertical soil reaction for plane-strain conditions

$w$ vertical penetration of caisson

$\alpha$ soil-structure adhesion factor

$\beta$ inclination of caisson cutting face (flat $\left.=90^{\circ}\right)$

$\gamma_{\mathrm{c}}$ caisson wall unit weight

$\gamma_{\mathrm{s}}$ soil unit weight

$\theta, \phi$ parameters defining soil failure mechanism

\section{REFERENCES}

Benmebarek, S., Remadna, M. S., Benmebarek, N. \& Belounar, L. (2012). Numerical evaluation of the bearing capacity factor of ring footings. Comput. Geotech. 44, 132-138.

Bolton, M. D. \& Lau, C. K. (1993). Vertical bearing capacity factors for circular and strip footings on Mohr-Coulomb soil. Can. Geotech. J. 30, No. 6, 1024-1033.

BSI (2004). BS EN 1997-1: Eurocode 7: Geotechnical design part 1: General rules. London, UK: BSI.

Cassidy, M. J. \& Houlsby, G. T. (2002). Vertical bearing capacity factors for conical footings on sand. Géotechnique 52, No. 9, 687-692, https://doi.org/10.1680/geot.2002.52.9.687.

Dunne, H. \& Martin, C. (2017). Capacity of rectangular mudmat foundations on clay under combined loading. Géotechnique 67, No. 2, 168-180, https://doi.org/10.1680/jgeot.16.P.079.

Frydman, S. \& Burd, H. J. (1997). Numerical studies of bearingcapacity factor $N_{\gamma}$. J. Geotech. Geoenviron. Engng 123, No. 1, $20-29$.

Hansen, J. B. (1970). A revised and extended formula forbearing capacity, bulletin 28, pp. 5-11. Copenhagen, Denmark: Danish Geotechnical Institute.

Houlsby, G. T. \& Martin, C. M. (2003). Undrained bearing capacity factors for conical footings on clay. Géotechnique 53, No. 5, 513-520.

Makrodimopoulos, A. \& Martin, C. M. (2006). Lower bound limit analysis of cohesive-frictional materials using second-order cone programming. Int. J. Numer. Methods Engng 66, No. 4, 604-634.

Makrodimopoulos, A. \& Martin, C. M. (2007). Upper bound limit analysis using simplex strain elements and second-order cone programming. Int. J. Numer. Analyt. Methods Geomech. 31, No. 6, 835-865.

Makrodimopoulos, A. \& Martin, C. M. (2008). Upper bound limit analysis using discontinuous quadratic displacement fields. Communs Numer. Methods Engng 24, No. 11, 911-927.

Martin, C. M. (2011). The use of adaptive finite-element limit analysis to reveal slip-line fields. Géotechnique Lett. 1, No. 2, 23-29, https://doi.org/10.1680/geolett.11.00018.

Martin, C. \& White, D. (2012). Limit analysis of the undrained bearing capacity of offshore pipelines. Géotechnique 62, No. 9, 847-863, https://doi.org/10.1680/geot.12.OG.016.

Meyerhoff, G. G. (1951). The ultimate bearing capacity of foundations. Géotechnique 2, No. 4, 301-332, https://doi.org/ 10.1680/geot.1951.2.4.301.

Meyerhof, G. G. \& Koumoto, T. (1987). Inclination factors for bearing capacity of shallow footings. J. Geotech. Engng 113, No. 9, 1013-1018.

O’Dwyer, K. G., McCabe, B. A., Sheil, B. B. \& Hernon, D. P. (2018). Blackpool south strategy project: analysis of pipe jacking 
records. Proceedings of Civil Engineering Research in Ireland (CERI 2018), Dublin, Ireland.

O’Dwyer, K. G., McCabe, B. A. \& Sheil, B. B. (2020). Interpretation of pipe-jacking and lubrication records for drives in silty sand. Underground Space 5, No. 3, 199-209, https://doi.org/ 10.1016/j.undsp.2019.04.001.

Prandtl, H. G. (1922). Über die Harte Plastischer Körper. Nachrichten von der Gesellschaft der Wissenschaften zu Göttingen, Mathematisch-Physikalische Klasse, 1920, pp. 75-85 (in German).

Royston, R. (2018). Investigation of soil-structure interaction for large diameter caissons. DPhil thesis, University of Oxford, Oxford, UK.

Royston, R., Sheil, B. B. \& Byrne, B. W. (2016). Bearing capacity beneath tapered blades of open dug caissons in sand. In Proceedings of civil engineering research in Ireland (ed. J. Goggins), pp. 473-478. Galway, Ireland: National University of Ireland.
Royston, R., Sheil, B. B. \& Byrne, B. W. (2020). Monitoring the construction of a large-diameter caisson in sand. Proc. Instn Civ. Engrs - Geotech. Engng, https://doi.org/10.1680/jgeen.19. 00266 .

Salgado, R., Lyamin, A., Sloan, S. \& Yu, H. (2004). Two- and three-dimensional bearing capacity of foundations in clay. Géotechnique 54, No. 5, 297-306, https://doi.org/10.1680/geot. 2004.54.5.297.

Sheil, B., Royston, R. \& Byrne, B. (2018). Real-time monitoring of large-diameter caissons. In Proceedings of China-Europe conference on geotechnical engineering (eds $\mathrm{W}$. $\mathrm{Wu}$ and H.-S. Yu), pp. 725-729. Cham, Switzerland: Springer.

Vesic, A. S. (1975). Bearing capacity of shallow foundations. In Foundation engineering handbook (eds H. F. Winterkorn and H.-Y Fang), ch. 3, pp. 121-147. New York, NY, USA: Van Nostrand Reinhold Company, Inc.

Zhao, L. \& Wang, J. H. (2008). Vertical bearing capacity for ring footings. Comput. Geotech. 35, No. 2, 292-230. 